\title{
Recommendations of the Romanian Society of Rheumatology regarding the management of patients with rheumatic diseases in the context of the SARS-CoV-2 pandemic
}

\author{
Catalin Codreanu ${ }^{1,2,3}$, Ruxandra Ionescu ${ }^{1,2,4}$, Denisa Predeteanu ${ }^{1,2,4}$, Elena Rezus ${ }^{1,5,6}$, \\ Magda Parvu ${ }^{1,2,7}$, Corina Mogosan ${ }^{1,2,3}$, Claudiu C. Popescu ${ }^{1,2,3}$, Simona Rednic ${ }^{1,8,9}$ \\ ${ }^{1}$ Romanian Society of Rheumatology \\ 2"Carol Davila" University of Medicine and Pharmacy, Bucharest, Romania \\ 3"Dr. Ion Stoia" Clinical Center for Rheumatic Diseases, Bucharest, Romania \\ 4"Sf. Maria" Clinical Hospital, Bucharest, Romania \\ 5"Grigore T. Popa" University of Medicine and Pharmacy, Iasi, Romania \\ ${ }^{6}$ Clinical Rehabilitation Hospital, Iasi, Romania \\ ${ }^{7}$ Colentina Clinical Hospital, Bucharest, Romania \\ 8"Iuliu Hatieganu" University of Medicine and Pharmacy, Cluj-Napoca, Romania \\ ${ }^{9}$ County Emergency Clinical Hospital, Cluj-Napoca, Romania
}

\begin{abstract}
SARS-CoV-2 (severe acute respiratory syndrome coronavirus 2 ) is responsible for the current pandemic, causing so far over 100.000 cases and more than 4500 deaths in Romania. Clinical manifestations are variable, ranging from mild forms (fever, dry cough, dyspnea, tachypnea, asthenia, myalgia) to severe bilateral pneumonia (COVID-19). Generally, patients with inflammatory/autoimmune rheumatic diseases have an increased risk of infections compared to the general population, especially if under treatment with immunosuppressive therapies. In the absence of infection or exposure to SARS-CoV-2, the use of specific drugs (non-steroidal anti-inflammatory drugs - NSAIDs; glucocorticoids - GC; conventional synthetic - csDMARDs, targeted synthetic - tsDMARDs and biologic disease-modifying anti-rheumatic drugs - bDMARDs, denosumab) should be unaffected. In patients with exposure to SARS-Co V-2, but without symptoms of COVID-19, NSAIDs, hydroxychloroquine, sulfasalazine and, in specific cases, IL-6 inhibitors may be continued, methotrexate, leflunomide, non-anti-IL-6 bDMARDs, tsDMARDs and immunosuppressants should be temporarily discontinued until a negative result for SARS-CoV-2 or for up to 2 weeks asymptomatic state for specific post-epidemiological COVID-19 symptoms. In patients with confirmed or suspected COVID-19 infection, non-anti-IL-6 bDMARDs, tsDMARDs, methotrexate, leflunomide, sulfasalazine and immunosuppressants must be temporarily discontinued. In such particular cases, IL-6 inhibitors and hydroxychloroquine may be continued, depending on the clinical context. In forms with severe respiratory manifestations, NSAIDs must be stopped. In all cases, non-essential medical consultations and maneuvers should be reduced where appropriate, with optimal use of telemedicine. Social distancing, facial masks and constant hand hygiene is advised for all patients, according to national and international recommendations.
\end{abstract}

Keywords: SARS-CoV-2, rheumatic diseases, Romanian Society of Rheumatology recommendations

\section{INTRODUCTION. NOMENCLATURE}

According to the World Health Organization (WHO) nomenclature, the condition called "coronavirus disease 2019", or abbreviated COVID-19 is caused by an RNA virus belonging to the coronavirus family, called "severe acute respiratory syndrome coronavirus 2", abbreviated SARS-CoV-2.
Coronaviruses were discovered in the 1930 s, the name comes from the Latin term "coronam", used to describe the appearance generated by spicules arranged on the surface of virions, observed under the electron microscope and resembling a crown. They are widespread in nature, causing various diseases, especially respiratory and digestive disease, in mam- 
mals and birds. After 1960, a number of 6 species of coronaviruses that cause disease in humans were identified:

- 4 "common" coronaviruses, endemic (named 229E, NL63, OC43 and HKU1), which cause "common" respiratory disease, manifested by rhinitis or rhino-pharyngitis (coronaviruses are the second etiology of infectious rhinitis, after rhinoviruses);

- 2 other species (of which one species with two strains) cause a potentially severe respiratory impairment:

- SARS-CoV (severe acute respiratory syndrome coronavirus), which caused an epidemic in Asia, spreading to other parts of the world, during 2002-2003;

- MERS-CoV (Middle East respiratory syndrome-related coronavirus), which caused an epidemic in the Middle East in 2012;

- SARS-CoV-2 (severe acute respiratory syndrome coronavirus 2) is a strain of SARS-CoV, to which it has an important genetic similarity. The first cases of human disease were reported in Wuhan, China, in December 2019. On January 7, 2020, the Chinese Center for Disease Prevention and Control isolated a new coronavirus from a patient's pharyngeal exudate, identifying it as the etiological agent of the Wuhan pneumonia cluster. WHO named the virus "2019-nCov" and the disease caused by it "COVID-19". The name of the new virus was later changed to "severe acute respiratory syndrome coronavirus 2" or SARSCoV-2. The genetic sequence of SARS$\mathrm{CoV}-2$ was made public by Chinese researchers on January 12, 2020: its RNA is $96 \%$ identical with that of SARS-CoV.

Given that the condition has recently been described, knowledge of the epidemiology, pathogenesis and clinical manifestation of the disease is limited and constantly changing. Major interest in the subject has led to the emergence of a large number of communications and publications on COVID-19, which is growing exponentially. The practitioner must exercise caution in interpreting the presented information, especially regarding the robustness of scientific evidence and its credibility.

Rheumatic diseases represent a group of disorders with various pathogenic mechanisms of immuno-inflammatory or degenerative type and frequent systemic manifestations, which in the context of the SARS-CoV-2 pandemic require a complex evaluation and individualized therapeutic approach. The following is a summary of the main data on SARSCoV-2 infection that have implications for the management of patients with rheumatic diseases. As new information becomes available, these recommendations will be updated.

\section{BRIEF INFORMATION ON THE CURRENT EPIDEMIOLOGICAL CONTEXT AND SARS-COV-2 INFECTION}

\section{Epidemiology}

Following the first outbreak in Wuhan, SARSCoV-2 spread rapidly in China, prompting WHO to declare a global health emergency on 30 January 2020. The virus spread was rapid, with the first cases in Europe reported in January 2020. The spread of the epidemic to many countries, on all continents, led WHO to recognize the pandemic nature of COVID-19 on March 11, 2020. The infection is currently pandemic, spreading to 188 countries, on all continents: more than 31 million cases and almost one million deaths were reported (according to Johns Hopkins University, https://coronavirus.jhu.edu/ map.html, accessed 21 September 2020). At the same time, over one hundred thousand cases and more than four thousand deaths were registered in Romania. The real number of cases is severely underestimated, being considered as at least 10 times higher than the number of confirmed cases. The natural reservoir for SARS-CoV-2 is richly represented: the virus easily passes from one species to another, frequently using an intermediate host (from bats to humans).

\section{Pathogenesis [1,2]}

Coronaviruses are lipo-protein-wrapped viruses that contain a single large RNA chain $[3,4]$, which together with $\mathrm{N}$ proteins forms a nucleocapsid. The integrity of the lipo-protein coating is important for the survival of the virus. Hand hygiene and surface disinfection recommendations are based on the fact that the virus is destroyed by applying alcoholic solutions with a concentration of over $70^{\circ}$ or by washing with soap and water. The viral envelope contains 4 types of proteins: glycoprotein $\mathrm{S}$, which is the structural protein of the spikes, with 2 subtypes (S1 and S2), envelope protein E, membrane protein and hemagglutinin esterase. 
Like most viruses, SARS-CoV-2 enters cells it infects through receptor-mediated endocytosis, with the most commonly used receptor being angiotensin 2 conversion enzyme (angiotensin convertase 2, ACE2), expressed on the surface of many cells in the body, including nasopharyngeal epithelial cells and pulmonary alveolar epithelial cells (type AT2) [5]. An important polymorphism of ACE2 expression has been described in various populations, which could intervene in modulating the genetic predisposition to SARS-CoV-2 infection.

The pathogenicity and virulence of the virus are determined by the structural proteins in the viral spicules (essential for penetration into infected cells) which are composed of 2 domains: S1- contains receptor-binding domain responsible for binding the virus to the membrane receptor and S2 - contains functional elements involved in cell membrane fusion.

The entry mechanism inside the cells uses cellular proteases, including: Transmembrane Serine Protease 2 (TMPRSS2) - which cleaves the spike and facilitates penetration through the cell membrane, human airway trypsin-like protease (HAT), catechins, adaptor-associated kinase 1 (AAK1), which favors endocytosis.

SARS-CoV-2 has in its composition non-structural proteins (nsp), which are able to inhibit innate immune response and thus favor viral replication.

After entering the cells, SARS-CoV-2 releases its RNA into the cytoplasm of infected cells, where the viral genome is replicated and determines the synthesis of viral proteins, using the resources of the host cell. These viral proteins are assembled into virions, which will then be transported in vesicles to the outside of the cell, allowing the infection of new cells in the host organism.

SARS-CoV-2 has high infectiousness and the transmission is realized by at least two ways:

- direct human-to-human contact [6], mainly through respiratory drops (similar to influen$\mathrm{za}$ ), which are produced by an infected person when coughing, sneezing or talking; the virus contained therein may infect another person if it comes into contact with the nasal, oral or ocular mucous membranes. Respiratory drops usually do not spread over a distance of more than 2 meters (hence the recommendation of social distancing) and do not persist in the air; they may, however, be deposited on surfaces;

- indirect contact: viral particles spread by infected persons can be deposited on various surfaces. Other persons contaminate their hands by touching these surfaces and get infected by contact with their own mucous membranes;

- the virus has been detected in the blood and stool of infected persons, but it is not clear to what extent fecal-oral transmission contributes to the spread of the disease;

- it is not clear whether the virus can be transmitted from mother to fetus, or through breast milk.

The maximum risk of contagiousness appears to be when the infected person is symptomatic, since viral elimination is increased at the time of symptomatic onset, decreasing over the next few daysweeks. There is a possibility of transmission of the disease in asymptomatic forms of infection or in the pre-symptomatic phase of infection (in the incubating phase of the disease, usually 1-3 days before the onset of symptoms). Detection of viral RNA in nasopharyngeal samples does not necessarily mean that the person can transmit the infection, the acquired infection being dependent on the viral load.

There is no conclusive data on the possibility of re-infection with SARS-CoV-2 after COVID-19 resolution. People infected with SARS-CoV-2 develop an immune response [3], which involves several protective systems of the body:

- the development of an innate immune response is the first line of defense, which involves a significant number of cytokines and chemokines [7], mainly with an increased synthesis of interferons, as well as the concomitant development of an inflammatory response, which will recruit various effector cells responsible for the destruction and elimination of the virus;

- an adaptive immune response with antibody synthesis, initially IgM and then IgG (both types can be measured in the patient's serum) is subsequently developed. Preliminary data show that these antibodies are protective, but it is not known whether the protective response occurs in all those infected and what is the duration of the protection they provide. Apparently, there is a directly proportional relationship between the severity of clinical manifestations (which is correlated with the degree of viral multiplication) and the formation of protective antibodies. 


\section{Clinical manifestations. Laboratory tests. Diagnosis}

The incubating period of the disease varies between 1 and 14 days, with an average of 4-5 days after the infectious exposure.

Clinical manifestations are variable (Table 1), usually including: fever, dry cough, dyspnea, tachypnea, asthenia, myalgia [8]. Anosmia and ageusia have been reported. Less often the following manifestations can occur: headache, rhinorrhea, odynophagia, diarrhea, nausea. There are a significant number of reports on the important clinical polymorphism of the disease.

TABLE 1. Clinical forms of COVID-19

\begin{tabular}{|l|l|}
\hline clinical forms (frequency) & clinical manifestations \\
\hline 1. mild form (80\%) & $\begin{array}{l}\text { without lung damage or mild } \\
\text { involvement }\end{array}$ \\
\hline $\begin{array}{l}\text { 2. forms with moderate or } \\
\text { severe pneumonia (15\%) }\end{array}$ & $\begin{array}{l}\text { dyspnea, tachypnea ( } \geq 30 / \\
\text { minute), } \mathrm{SpO}_{2} \leq 93 \%, \mathrm{PaO}_{2} / \\
\mathrm{FiO}_{2}-300 \text { and/or pulmonary } \\
\text { infiltration }>50 \% \text {, installed } \\
\text { within 24-48 hours }\end{array}$ \\
\hline 3. critical forms (5\%) & $\begin{array}{l}\text { acute respiratory failure, septic } \\
\text { shock, multi-organic insufficiency }\end{array}$ \\
\hline
\end{tabular}

There are asymptomatic cases (apparently numerically significant), but their frequency is unclear, as asymptomatic people are usually not tested.

Symptomatic cases vary significantly in severity, from mild forms of the disease (apparently, the majority), to severe forms (usually with significant lung damage), some critical (acute respiratory failure, shock, multi-organic insufficiency), potentially fatal.

In severe forms of the disease, SARS-CoV-2 exceeds the physiological defense mechanisms of the body, a rapid viral replication occurs, which causes direct cytopathic effects, as well as the appearance of a massive inflammatory infiltration into the lung tissue. An exaggerated inflammatory response contributes essentially to the worsening of lung damage, with the synthesis and rapid release of an excessive amount of cytokines, which end up increasing tissue lesions, with severe clinical consequences. SARSCoV-2 binds to ACE2 receptors expressed on the surface of type 2 pulmonary epithelial cells, excessively activates innate and acquired immunity, with massive synthesis of cytokines, increased capillary permeability, accumulation of fluids and cells in the alveoli, dyspnea, severe respiratory failure, coagulation disorders in various organs, complications which can cause death. A special mention refers to the coagulation disorders and fibrinolysis secondary to the increased plasmin level resulting from the cleavage of plasminogen under the action of urokinase (in body fluids) or tissue-like plasminogen activator (in plasma) with D-dimers increase and thrombocytopenia, which correlate with increased risk of death [9-12].

"Cytokines release syndrome" is a systemic inflammatory response of the body, found in viral infections or triggered by some immunological therapies, for example CAR-T cell therapy (chimeric antigen receptor T-cell therapy), caused by the sudden release of a large amount of various cytokines, which appears to be involved in the pathogenesis of some of the severe pulmonary manifestations of COVID-19.

Severe forms can occur at any age, and in the absence of any comorbid associations, but most commonly occur in elderly (over 65 years of age) and those with associated conditions (lung disease, heart disease, obesity, diabetes mellitus, chronic kidney disease, neoplasia, immunosuppressive conditions). The mortality rate varies widely in different cohorts (generally between 1-3\%), but severe forms of the disease show significant mortality.

The manifestations of the disease in children are similar to those of the adult, but usually milder. The occurrence of Kawasaki-like manifestations in children has been reported in apparent relationship with SARS-CoV-2 infection, but the pathogenic mechanism involved is still unclear.

Laboratory tests frequently highlight lymphopenia, LDH and transaminase increase. High levels of $\mathrm{C}$-reactive protein and ferritin are associated with severe forms, and increased D-dimers and lymphopenia are associated with increased mortality. Procalcitonin is usually normal, but it can increase in severe forms with lung damage.

Diagnosis of COVID-19 requires detection of SARS-CoV-2 RNA, the reference method being reverse transcription polymerase chain reaction ( $R T$ $P C R)$ in samples most commonly collected from the nasopharynx. Conducting tests requires a laboratory with special equipment and a high degree of biosecurity, as well as experienced personnel. Large differences in the accuracy of the tests performed have been reported (false positive and false negative results have been reported, with a sensitivity that can be only $60-71 \%$ ) [13]. Confirmation of diagnosis on the basis of highly suggestive clinical and epidemiological elements in the absence of virological tests (RT-PCR) is considered acceptable. 


\section{Treatment. Pharmacological interactions $[14,15]$}

There are no specific therapies approved for SARS-CoV-2 infection. The applied treatment is supportive, adapted to the form of the disease, including oxygen intake, and in critical forms respiratory support, preferably non-invasive when possible (positive pressure oxygen administration, on the mask).

A number of antiviral or immunomodulatory therapies are currently used "off-label" in the treatment of SARS-CoV-2 infection, being studied in many countries [16]. The communicated or published data to date are inconclusive or contradictory.

Of the antiviral therapies, so far remdesivir has presented the most promising results: according to preliminary data, published in the adaptive $\mathrm{COV}$ ID-19 Treatment Trial, treatment with remdesivir accelerates the healing process in severe forms of COVID-19, by shortening the average time to resolution by approximately $30 \%$; however, additional data on the potential use of remdesivir in the treatment of SARS-CoV-2 infection are required.

Hydroxychloroquine and chloroquine, alone or associated with azithromycin $[17,18]$, based on data demonstrating in vitro activity against SARS-CoV-2, were widely publicized and administered off-label or in clinical trials [19-26], in the hope that they could exert beneficial effects in patients infected with SARS-CoV-2. The clinical data published to date are inconclusive, and scientific cardiology associations have warned of the risk of severe arrhythmias and sudden death in patients treated with high doses of synthetic antimalarials and/or azithromycin and recommend caution in their use in patients with pre-existing heart conditions. Additional data from clinical trials clarifying potential efficacy as well as the toxicity risks of hydroxychloroquine in the treatment of patients with COVID-19 or in the prophylaxis of SARS-CoV-2 infection are needed.

Glucocorticoids, in various doses and therapeutic regimens, have been used with controversial results in the treatment of COVID-19-related acute respiratory failure syndrome. Receptor blockers for IL-6, tocilizumab [27,28] and sarilumab [29], and IL-1 blockers (anakinra [30,31]) have been used off-label for the treatment of cytokine release syndrome, which may occur in severe forms of lung damage in COVID-19. Clinical trials are currently underway to confirm their potential usefulness in the treatment of the disease. Clinical trials on the potential use of JAK inhibitors [32] are also under way.
The administration of plasma from COVID-19 convalescents, which may contain anti-SARSCoV-2 neutralizing antibodies, has been used experimentally, clinical trials are currently under way.

There are still no approved vaccines for SARS$\mathrm{CoV}-2$ infection, with numerous studies currently under way to develop a vaccine.

Starting from the SARS-CoV-2 interaction with the ACE2 receptor, it has been hypothesized, but still unconfirmed, that some drugs that increase the membrane expression of ACE2, such as ibuprofen, angiotensin-convertase inhibitors (e.g. enalapril and ramipril) or angiotensin receptor blockers (e.g. candesartan and valsartan), could increase the risk of SARS-CoV-2 infection and/or its severity. In the context of SARS-CoV-2 infection, the current recommendations maintain that there is no scientific data limiting the use of ibuprofen in patients who have an indication for this drug. In the same context, cardiology associations recommend that in patients who have an indication of treatment with angiotensin-convertase inhibitors or angiotensin receptor blockers, these drugs can be started or continued in full doses, necessary for the control of cardio-vascular disease.

\section{MANAGEMENT OF PATIENTS WITH INFLAMMATORYIAUTOIMMUNE RHEUMATIC DISEASES IN THE CONTEXT OF THE SARS-COV-2 PANDEMIC [33-38]}

Risk of SARS-CoV-2 infection and severe forms of COVID-19 in patients with inflammatory/autoimmune rheumatic conditions [39]

Generally, patients with inflammatory/autoimmune rheumatic diseases (Table 2) have an increased risk of infections compared to the general population $[40,41]$, both because of the pathogenic mechanism of the disease, which involves immune system dysfunction, and because of immunosuppressive treatments commonly used to control these diseases $[42,43]$.

The mechanism that explains the increase of infectious risk in patients with inflammatory/autoimmune rheumatic diseases is complex. At least 3 factors are involved: the pathogenic process of the disease, including how it interferes with the physiological functions of the body's defenses, in particular the immune system; the presence of comorbidities, complications of rheumatic disease and general risk factors for infections; the anti-rheumatic thera- 
TABLE 2. Main rheumatic diseases with increased risk of immunosuppression

\begin{tabular}{|l|l|}
\hline rheumatic disease & disease-related risk of immunosuppression \\
\hline rheumatoid arthritis & $\begin{array}{l}\text { intermediate/high/very high } \\
\text { the risk increases significantly in those with systemic forms, visceral } \\
\text { involvement (e.g. interstitial lung disease and/or pulmonary } \\
\text { hypertension), vasculitis }\end{array}$ \\
\hline adult Still disease & high \\
\hline juvenile idiopathic arthritis & high/intermediate \\
\hline spondyloarthritis & intermediate/high \\
\hline psoriatic arthritis & intermediate/high \\
\hline systemic lupus erythematosus & high/very high \\
\hline scleroderma & $\begin{array}{l}\text { high/very high } \\
\text { the risk increases significantly in those with pulmonary hypertension }\end{array}$ \\
\hline $\begin{array}{l}\text { polymyositis, dermatomyositis, antisynthetase } \\
\text { syndrome }\end{array}$ & $\begin{array}{l}\text { high/very high } \\
\text { the risk increases significantly due to weakness of the respiratory } \\
\text { muscles, as well as in the case of interstitial lung disease }\end{array}$ \\
\hline mixed connective tissue disease & high \\
\hline primary Sjögren syndrome & intermediate/high \\
\hline vasculitis (all except $*$ & high/very high \\
\hline IgA vasculitis * & high \\
\hline IgG4 related disease & high/very high \\
\hline self-inflammatory syndromes & high \\
\hline rheumatic polymyalgia & intermediate \\
\hline $\begin{array}{l}\text { non-inflammatory or inflammatory rheumatic } \\
\text { diseases that cause important deformities of the } \\
\text { chest (severe cyphosis/scoliosis) }\end{array}$ & $\begin{array}{l}\text { high/very high } \\
\text { the risk is increased by significant involvement of the shape/capacity } \\
\text { of the rib cage and respiratory movements }\end{array}$ \\
\hline
\end{tabular}

pies, which may have a dual influence (on the one hand, by proper control of the immuno-inflammatory process, may favor the defense against infections; on the other hand, by exerting a net immunosuppressive effect, they may increase the risk of an infectious disease or a more severe manifestation thereof).

The presence of risk factors and comorbidities or visceral complications of rheumatic diseases [44] may further increase the risk of immunosuppression in patients with inflammatory/autoimmune rheumatic diseases (Table 3).

TABLE 3. Risk factors and comorbidities associated with immunosuppression in patients with inflammatory/ autoimmune rheumatic diseases

\begin{tabular}{|l|l|}
\hline risk factors & comorbidities \\
\hline age & obesity \\
male sex & diabetes \\
smoking & interstitial lung disease \\
intense activity of rheumatic & pulmonary hypertension \\
disease & other lung diseases \\
& ischemic heart disease \\
& glomerulonephritis \\
& renal \\
& neutropenia \\
& liver disease \\
\hline
\end{tabular}

The use of anti-rheumatic immunosuppressive therapies is probably more relevant in defining the risk of immunosuppression compared to the risk of the rheumatic disease itself. The main conventional synthetic (csDMARDs), targeted synthetic (tsDMARDs) and biological disease-modifying anti-rheumatic drugs (bDMARDs) that increase the risk of immunosuppression are listed in Table 4.

TABLE 4. Therapies used in the treatment of rheumatic diseases, which increase the risk of immunosuppression

\begin{tabular}{|c|c|c|}
\hline csDMARDs* & $b D M A R D^{* \& \#}$ & $\begin{array}{l}\text { tsDMARDs } \\
\text { and other } \\
\text { procedures* }\end{array}$ \\
\hline $\begin{array}{l}\text { methotrexate } \\
\text { (high risk) } \\
\text { leflunomide } \\
\text { (high risk) } \\
\text { cyclosporin } \\
\text { (high risk) } \\
\text { cyclophosphamide } \\
\text { (very high risk) } \\
\text { mycophenolate } \\
\text { mofetil } \\
\text { (very high risk) } \\
\text { tacrolimus } \\
\text { (very high risk) }\end{array}$ & $\begin{array}{l}\text { all TNF blockers, } \\
\text { rituximab (especially } \\
\text { in the first year post- } \\
\text { administration) } \\
\text { tocilizumab } \\
\text { and sarilumab } \\
\text { (may affect CRP } \\
\text { synthesis), abatacept, } \\
\text { secukinumab, } \\
\text { ixekizumab, } \\
\text { belimumab }\end{array}$ & $\begin{array}{l}\text { JAK inhibitors } \\
\text { apremilast } \\
\text { plasmapheresis } \\
\text { stem cell } \\
\text { transplantation }\end{array}$ \\
\hline
\end{tabular}

* the risk of immunosuppression increases significantly if therapies are used in combination; \& for patients treated with denosumab there is no data on increased risk of immunosuppression;

\# any targeted biological or synthetic therapy places the patient in the high or very high risk category. bDMARDs - biological diseasemodifying antirheumatic drugs, csDMARDs - conventional synthetic DMARDs; tsDMARDs - targeted synthetic DMARDs.

Given that the intervention of various immunosuppression-inducing mechanisms in patients with 
inflammatory/autoimmune rheumatic diseases may be manifested in the most varied combinations, for risk assessment in various clinical situations it is reasonable to apply a risk stratification strategy, based on the identification of individual risk factors, Thus, for the same disease, for example rheumatoid arthritis (RA), the risk of immunosuppression may be extremely different, depending on a combination of other factors (Table 6).

TABLE 5. Risk of immunosuppression based on exposure to glucocorticoids

\begin{tabular}{|l|l|}
\hline $\begin{array}{l}\text { doses of glucocorticoids, } \\
\text { pharmacological associations }\end{array}$ & risk of immunosuppression \\
\hline$\leq 10 \mathrm{mg} /$ day, monotherapy & low risk \\
\hline $\begin{array}{l}\leq 10 \mathrm{mg} / \text { day in combination with } \\
\text { other immunosuppressants }\end{array}$ & intermediate/high risk \\
\hline $10-19 \mathrm{mg} /$ day, monotherapy & intermediate risk \\
\hline $\begin{array}{l}10-19 \mathrm{mg} / \text { day in combination } \\
\text { with other immunosuppressants }\end{array}$ & high/very high risk \\
\hline$\geq 20 \mathrm{mg} /$ day & high/very high risk \\
\hline
\end{tabular}

Given the experience of other infectious diseases whose frequency increases in relation to rheumatic conditions and their specific therapies, it is clear that there may be large differences in risk increase depending on the disease and treatment type (e.g. tuberculosis after TNF blockers or herpes zoster after JAK inhibitors); specific data related to SARS$\mathrm{CoV}-2$ infection are needed in patients with inflammatory/autoimmune rheumatic diseases. It should be noted that there is no data on the cohorts published to date to show an increase in the risk of SARSCoV-2 infection in patients with inflammatory/autoimmune rheumatic diseases, including those treated with remissive therapies, except for patients treated with doses of more than $10 \mathrm{mg}$ of prednisone per day, where a higher risk of hospitalization for COVID-19 has been identified.

TABLE 6. Risk of immunosuppression in rheumatoid arthritis (RA)

\begin{tabular}{|l|l|l|}
\hline $\begin{array}{l}\text { clinical situation of a } \\
\text { 45-year-old RA patient }\end{array}$ & Treatment & $\begin{array}{l}\text { risk of } \\
\text { immunosuppression }\end{array}$ \\
\hline $\begin{array}{l}\text { without comorbidities, } \\
\text { stable RA, in remission }\end{array}$ & sulfasalazine & no increased risk \\
\hline $\begin{array}{l}\text { without comorbidities, } \\
\text { stable RA, in remission }\end{array}$ & $\begin{array}{l}\text { sulfasalazine } \\
+10 \mathrm{mg} \\
\text { prednisone/day }\end{array}$ & intermediate risk \\
\hline $\begin{array}{l}\text { without comorbidities, } \\
\text { stable RA, in remission }\end{array}$ & $\begin{array}{l}\text { methotrexate }+ \\
\text { TNFalpha blocker }\end{array}$ & high risk \\
\hline $\begin{array}{l}\text { diabetes mellitus, stable } \\
\text { RA, in remission }\end{array}$ & $\begin{array}{l}\text { methotrexate }+ \\
\text { TNFalpha blocker }\end{array}$ & very high risk \\
\hline $\begin{array}{l}\text { no comorbidities, high- } \\
\text { activity RA }\end{array}$ & $\begin{array}{l}\text { methotrexate }+ \\
\text { TNFalpha blocker }\end{array}$ & very high risk \\
\hline
\end{tabular}

Guidelines for antirheumatic treatment in patients with inflammatory/autoimmune rheumatic diseases in the context of the SARS-CoV-2 pandemic

Appropriate control of the activity of the disease in inflammatory/autoimmune rheumatic diseases, obtained by continuing an efficient therapeutic regimen, is considered to reduce the risk of developing an infectious disease $[45,46]$. For this reason the generally accepted recommendation is that patients who do not have clinical signs of COVID-19 should continue without changes their remissive or immunosuppressants, without the need for prior testing for SARS-CoV-2.

In the published cohorts of patients with COVID-19 there is no data showing that in patients requiring chronic immunosuppressive treatment, prophylactic discontinuation of the disease would reduce the risk of infection with SARS-CoV-2. Furthermore, recently published data show that in patients with chronic inflammatory rheumatic conditions treated with biological or targeted synthetic drugs, there has been no increase in the risk of respiratory or life-threatening complications of SARS$\mathrm{CoV}-2$ infection compared to the general population.

In contrast, in patients who have an inflammatory rheumatic disease and develop COVID-19, as in any severe infection, temporary discontinuation of remissive or immunosuppressive medication is necessary, which can be resumed after the resolution of the infection. The decision to discontinue therapy should be made on the basis of an individual assessment evaluation the ratio between the potential risk of worsening SARS-CoV-2 infection and the flare risk of the rheumatic disease.

These general recommendations can be customized depending on exposure to SARS-CoV-2 or the presence of clinical signs of COVID-19.

As a general rule, glucocorticoids, regardless of SARS-CoV-2 exposure or infection:

- may be used if they have an indication in the treatment of rheumatic disease, but in the lowest dose allowing the control of the rheumatic disease;

- for patients on glucocorticoids and requiring dose reduction or discontinuation of treatment, discontinuation should never be sudden. 
Recommended conduct in the absence of infection or exposure to SARS-CoV-2

In patients with active or newly diagnosed inflammatory rheumatic disease, depending on the clinical specifics of the case, any of the following therapies may be recommended:

- initiation of (NSAIDs) or glucocorticoids in low doses ( $\leq 10 \mathrm{mg}$ prednisone equivalent/ day);

- initiation of a csDMARD (methotrexate, leflunomide, sulfasalazine, hydroxychloroquine) or its change, as appropriate; if hydroxychloroquine is not commercially available, it will be replaced by other csDMARDs;

- for patients with high disease activity, despite optimal treatment with csDMARDs, treatment with a bDMARD (all classes) or a tsDMARD may be initiated;

- in patients with systemic lupus erythematosus, hydroxychloroquine is initiated or continued in full doses, including in the event of pregnancy [47-49]; treatment with belimumab may be initiated if necessary;

- in patients with severe systemic inflammatory diseases or life-threatening organ damage (e.g. severe systemic vasculitis or lupus nephritis), immunosuppressants or high-dose glucocorticoids may be initiated.

In patients with stable inflammatory arthritis under treatment, it is recommended to continue treatment without modification, and the use of any of the following therapies is allowed:

- csDMARDs (methotrexate, leflunomide, sulfasalazine, hydroxychloroquine);

- immunosuppressants (azathioprine, cyclophosphamide, cyclosporin, mycophenolate mofetil, tacrolimus);

- bDMARD (all classes);

- tsDMARDs (JAK inhibitors);

- NSAIDs.

In patients with osteoporosis, treatment with denosumab may be initiated or continued, with the possibility of widening the interval between administrations up to a maximum of 8 months (if necessary, in order to avoid the presence in a medical unit).

Recommended conduct in patients with inflammatory/autoimmune rheumatic diseases and exposure to SARS-Co V-2, but without symptoms of COVID-19

In this case, the following approach is recommended, according to the current anti-rheumatic therapy:
- hydroxychloroquine, sulfasalazine and NSAIDs may be continued;

- temporarily discontinued for methotrexate and leflunomide, non-anti-IL-6 bDMARDs, JAK inhibitors and immunosuppressants until a negative result for SARS-CoV-2 or for up to 2 weeks asymptomatic for specific post-epidemiological COVID-19 symptoms;

- depending on the case, IL-6 inhibitors may be continued, according to the decision of the attending physician.

Recommended conduct in patients with inflammatory/autoimmune rheumatic diseases and confirmed or suspected COVID-19 infection

In this case, the following approach is recommended, differentiated according to the current anti-rheumatic therapy:

- the following therapies will be temporarily interrupted:

- non-anti-IL-6 biologics;

- JAK inhibitors;

- methotrexate, leflunomide, sulfasalazine, immunosuppressants.

- in some situations, IL-6 inhibitors may be continued, depending on the particularities of the case, according to the decision of the attending physician.

- existing data, including expert opinion on the continuation and cessation of hydroxychloroquine therapy are contradictory. Depending on the particularities of the case, hydroxychloroquine treatment may be continued, with particular attention to potential cardiovascular adverse effects.

- in forms with severe respiratory manifestations, NSAIDs are interrupted.

\section{GENERAL PRECAUTIONS RECOMMENDED IN RHEUMATOLOGY PRACTICE IN THE CONTEXT OF THE SARS-COV-2 PANDEMIC [50-54]}

The risk of unfavorable outcome of COVID-19 appears to be mainly related to general risk factors, such as age and comorbidities, mainly: respiratory, cardiovascular and metabolic (including obesity) associated conditions. Patients with these risk factors should be subject to a special SARS-CoV-2 infection prevention program, including rigorous containment action and protection measures against exposure to 
potential infectious contacts compared to the general population.

Patients with inflammatory/autoimmune rheumatic diseases or undergoing immunosuppressive therapies should receive general recommendations of social distancing (minimum 2 meters) as well as proper and constant hand hygiene. Wearing medical masks covering the nose and mouth appears to have a significant effect in reducing the risk of infection, their use being recommended not only in enclosed spaces, but also in open ones with crowded spaces, where social distancing cannot be properly noticed.

It is also recommended to systematically reduce the risk of infection with SARS-CoV-2 by limiting the exposure of immunosuppressed patients to an increased risk of contagion related to non-essential medical consultations and maneuvers. The aim will be to reduce consultations and maneuvers involving the physical presence of the patient at rheumatology service providers:

- optimal use of telemedicine: with firm preference for carrying out remote assessments and formulating the necessary recommendations, in all cases where this is possible;

- reducing the frequency of laboratory monitoring (where possible);

- increasing the interval between administrations for intravenous medication (where possible).

For patients with RA who need an evaluatio in terms of disease activity, consideration should be given to the possibility of using the RAPID3 [55] and RAID [56,57] questionnaires, which allows the evaluation of the disease activity in a remote consultation.

Medical maneuvers which involve the patient's presence in the outpatient department/hospital (infusion therapy, local therapies, laboratory or imaging investigations) that which cannot be postponed, should be done only as a result of a prior appointment, ensuring the proper social distancing of patients in rheumatology services, as well as performing safe diagnostic and treatment maneuvers for both the patient and the medical staff. Screening for symptoms or epidemiological risk of COVID-19 is mandatory before allowing patients access to the outpatient department/hospital; it is also mandatory for medical personnel to wear protective equipment, according to the degree of risk, as advised by the competent authorities.

Rheumatologists should continuously be aware of their role in the active detection of cases of COVID-19 in patients with rheumatic diseases, by:

- early detection of disease-specific symptoms;

- rigorous assessment of risk factors, including epidemiological questionnaires;

- RT-PCR testing recommendation for SARS$\mathrm{CoV}-2$, when indicated.

It is advisable, for the benefit of treated patients, to establish a close relationship with the patient's general practitioner, in order to delegate monitoring activities as well as the prescribed therapy. If there are deficiencies in the provision of anti-rheumatic medication (e.g. for hydroxychloroquine), the rheumatologist should find solutions for further therapy or modification of the therapeutic regimen.

Given that the pandemic is still evolving (infection is manifested by community transmission and cases periodically occur in health facilities) and that there are no specific therapies or vaccines, it is reasonable to implement a long-term program on reducing the risk of SARS-CoV-2 infection, both in patients with rheumatic diseases and in medical staff in rheumatology services. Such a program should contain clear rules of epidemiological triage, conduct towards patients and third parties, supply of sanitary materials, medicinal products and protective equipment. Compliance with the usual vaccination program for patients with inflammatory/autoimmune rheumatic diseases or who are undergoing immunosuppressive therapies should be considered, with particular attention to seasonal influenza and anti-pneumococcal vaccination.

The Romanian Society of Rheumatology will implement a systematic program of regular information of rheumatologists on the evolution of available data on the SARS-CoV-2 pandemic. Through cooperation with patient associations, general-purpose information materials on the recommended management for patients with rheumatic diseases in the context of the CoVID-19 pandemic will be developed and distributed. 


\section{REFERENCES}

1. Yuki K, Fujiogi M, Koutsogiannaki S. COVID-19 pathophysiology: $A$ review. Clin Immunol. 2020;215:108427.

2. Kanduc D, Shoenfeld Y. On the molecular determinants of the SARS-CoV-2 attack. Clin Immunol. 2020;215:108426.

3. Lee CY, Lin RTP, Renia L, Ng LFP. Serological Approaches for COVID-19: Epidemiologic Perspective on Surveillance and Control. Front Immunol. 2020;11:879.

4. Andersen KG, Rambaut A, Lipkin WI, Holmes EC, Garry RF. The proximal origin of SARS-CoV-2. Nat Med. 2020;26(4):450-2.

5. Sungnak W, Huang N, Becavin C, Berg M, Queen R, Litvinukova $M$, et al. SARS-CoV-2 entry factors are highly expressed in nasal epithelial cells together with innate immune genes. Nat Med. 2020;26(5):681-7.

6. Corman VM, Muth D, Niemeyer D, Drosten C. Hosts and Sources of Endemic Human Coronaviruses. Adv Virus Res. 2018;100:163-88.

7. Hirano T, Murakami M. COVID-19: A New Virus, but a Familiar Receptor and Cytokine Release Syndrome. Immunity. 2020;52(5):731-3.

8. Richardson S, Hirsch JS, Narasimhan M, Crawford JM, McGinn T, Davidson KW, et al. Presenting Characteristics, Comorbidities, and Outcomes Among 5700 Patients Hospitalized With COVID-19 in the New York City Area. JAMA. 2020.

9. Ji HL, Zhao R, Matalon S, Matthay MA. Elevated Plasmin(ogen) as a Common Risk Factor for COVID-19 Susceptibility. Physiol Rev. 2020;100(3):1065-75.

10. Teuwen LA, Geldhof V, Pasut A, Carmeliet P. Author Correction: COVID-19: the vasculature unleashed. Nat Rev Immunol. 2020.

11. Teuwen LA, Geldhof V, Pasut A, Carmeliet P. COVID-19: the vasculature unleashed. Nat Rev Immunol. 2020.

12. Tavazzi G, Civardi L, Caneva L, Mongodi S, Mojoli F. Thrombotic events in SARS-CoV-2 patients: an urgent call for ultrasound screening. Intensive Care Med. 2020;46(6):1121-3.

13. Ismail AA. Serological tests for COVID-19 antibodies: Limitations must be recognized. Ann Clin Biochem. 2020:4563220927053.

14. Favalli EG, Ingegnoli F, De Lucia O, Cincinelli G, Cimaz R, Caporali R. COVID-19 infection and rheumatoid arthritis: Faraway, so close! Autoimmun Rev. 2020;19(5):102523.

15. Sanders JM, Monogue ML, Jodlowski TZ, Cutrell JB. Pharmacologic Treatments for Coronavirus Disease 2019 (COVID-19): A Review. JAMA. 2020.

16. Perricone C, Triggianese P, Bartoloni E, Cafaro G, Bonifacio AF, Bursi $R$, et al. The anti-viral facet of anti-rheumatic drugs: Lessons from COVID-19. J Autoimmun. 2020;111:102468.

17. Rosenberg ES, Dufort EM, Udo T, Wilberschied LA, Kumar J, Tesoriero J, et al. Association of Treatment with Hydroxychloroquine or Azithromycin With In-Hospital Mortality in Patients With COVID-19 in New York State. JAMA. 2020.

18. Saleh M, Gabriels J, Chang D, Kim BS, Mansoor A, Mahmood E, et al. The Effect of Chloroquine, Hydroxychloroquine and Azithromycin on the Corrected QT Interval in Patients with SARS-CoV-2 Infection. Circ Arrhythm Electrophysiol. 2020.

19. Savarino A, Boelaert JR, Cassone A, Majori G, Cauda R. Effects of chloroquine on viral infections: an old drug against today's diseases? Lancet Infect Dis. 2003;3(11):722-7.

20. Geleris J, Sun Y, Platt J, Zucker J, Baldwin M, Hripcsak G, et al. Observational Study of Hydroxychloroquine in Hospitalized Patients with Covid-19. N Engl J Med. 2020.

21. Borba MGS, Val FFA, Sampaio VS, Alexandre MAA, Melo GC, Brito $\mathrm{M}$, et al. Effect of High vs Low Doses of Chloroquine Diphosphate as Adjunctive Therapy for Patients Hospitalized with Severe Acute Respiratory Syndrome Coronavirus 2 (SARS-CoV-2) Infection: A Randomized Clinical Trial. JAMA Netw Open. 2020;3(4):e208857.

22. Boulware DR, Pullen MF, Bangdiwala AS, Pastick KA, Lofgren SM, Okafor EC, et al. A Randomized Trial of Hydroxychloroquine as Postexposure Prophylaxis for Covid-19. N Engl J Med. 2020.

23. Monti S, Montecucco C. Can hydroxychloroquine protect patients with rheumatic diseases from COVID-19? Response to: ,Does hydroxychloroquine prevent the transmission of COVID-19?' by Heldwein and Calado and, SLE, hydroxychloroquine and no SLE patients with COVID-19: a comment' by Joob and Wiwanitkit. Ann Rheum Dis. 2020;79(6):e62.
24. Xie W, Wang Y, Zhang Z. Hydroxychloroquine reduces the risk of covid-19 in patients with rheumatic diseases: myth or reality? Ann Rheum Dis. 2020.

25. Parperis K. To consider or not antimalarials as a prophylactic intervention in the SARS-CoV-2 (COVID-19) pandemic. Ann Rheum Dis. 2020.

26. Moiseev S, Avdeev S, Brovko M, Novikov P, Fomin V. Is there a future for hydroxychloroquine/chloroquine in prevention of SARSCoV-2 infection (COVID-19)? Ann Rheum Dis. 2020.

27. Xu X, Han M, Li T, Sun W, Wang D, Fu B, et al. Effective treatment of severe COVID-19 patients with tocilizumab. Proc Natl Acad Sci U S A. 2020;117(20):10970-5.

28. Campochiaro C, Della-Torre E, Cavalli G, De Luca G, Ripa $M$, Boffini N, et al. Efficacy and safety of tocilizumab in severe COVID-19 patients: a single-centre retrospective cohort study. Eur J Intern Med. 2020;76:43-9.

29. Benucci M, Giannasi G, Cecchini P, Gobbi FL, Damiani A, Grossi V, et al. COVID-19 pneumonia treated with Sarilumab: a clinical series of eight patients. J Med Virol. 2020.

30. Cavalli G, De Luca G, Campochiaro C, Della-Torre E, Ripa M, Canetti D, et al. Interleukin-1 blockade with high-dose anakinra in patients with COVID-19, acute respiratory distress syndrome, and hyperinflammation: a retrospective cohort study. Lancet Rheumatol. 2020;2(6):e325-e31.

31. Aouba A, Baldolli A, Geffray L, Verdon R, Bergot E, Martin-Silva N, et al. Targeting the inflammatory cascade with anakinra in moderate to severe COVID-19 pneumonia: case series. Ann Rheum Dis. 2020.

32. Favalli EG, Biggioggero M, Maioli G, Caporali R. Baricitinib for COVID-19: a suitable treatment? Lancet Infect Dis. 2020.

33. Landewe RB, Machado PM, Kroon F, Bijlsma HW, Burmester GR, Carmona $L$, et al. EULAR provisional recommendations for the management of rheumatic and musculoskeletal diseases in the context of SARS-CoV-2. Ann Rheum Dis. 2020.

34. Mikuls TR, Johnson SR, Fraenkel L, Arasaratnam RJ, Baden LR, Bermas BL, et al. American College of Rheumatology Guidance for the Management of Rheumatic Disease in Adult Patients During the COVID-19 Pandemic: Version 1. Arthritis Rheumatol. 2020.

35. National Health Service UK. https://www.england.nhs.uk/ coronavirus/secondary-care/ (accessed on 15.06.2020).

36. British Society for Rheumatology UK. https://www.rheumatology.org. uk/practice-quality/covid-19-guidance (accessed on 15.06.2020).

37. Marotto D, Sarzi-Puttini P. What is the role of rheumatologists in the era of COVID-19? Autoimmun Rev. 2020;19(6):102539.

38. Licciardi F, Giani T, Baldini L, Favalli EG, Caporali R, Cimaz R. COVID-19 and what pediatric rheumatologists should know: a review from a highly affected country. Pediatr Rheumatol Online $\mathrm{J}$. 2020;18(1):35.

39. Favalli EG, Ingegnoli F, Cimaz R, Caporali R. What is the true incidence of COVID-19 in patients with rheumatic diseases? Ann Rheum Dis. 2020.

40. Favalli EG, Monti S, Ingegnoli F, Balduzzi S, Caporali R, Montecucco C. Incidence of COVID-19 in patients with rheumatic diseases treated with targeted immunosuppressive drugs: what can we learn from observational data? Arthritis Rheumatol. 2020.

41. Haberman R, Axelrad J, Chen A, Castillo R, Yan D, Izmirly P, et al. Covid-19 in Immune-Mediated Inflammatory Diseases - Case Series from New York. N Engl J Med. 2020.

42. D'Antiga L. Coronaviruses and Immunosuppressed Patients: The Facts During the Third Epidemic. Liver Transpl. 2020;26(6):832-4.

43. Siddiqi HK, Mehra MR. COVID-19 illness in native and immunosuppressed states: A clinical-therapeutic staging proposal. J Heart Lung Transplant. 2020;39(5):405-7.

44. Gianfrancesco M, Hyrich KL, Al-Adely S, Carmona L, Danila MI, Gossec L, et al. Characteristics associated with hospitalisation for COVID-19 in people with rheumatic disease: data from the COVID-19 Global Rheumatology Alliance physician-reported registry. Ann Rheum Dis. 2020.

45. Au K, Reed G, Curtis JR, Kremer JM, Greenberg JD, Strand V, et al. High disease activity is associated with an increased risk of infection in patients with rheumatoid arthritis. Ann Rheum Dis. 2011;70(5):785-91. 
46. Accortt NA, Lesperance T, Liu M, Rebello S, Trivedi M, Li Y, et al. Impact of Sustained Remission on the Risk of Serious Infection in Patients With Rheumatoid Arthritis. Arthritis Care Res (Hoboken). 2018;70(5):679-84.

47. Favalli EG, Agape E, Caporali R. Are patients with systemic lupus erythematosus at increased risk of severe COVID-19? J Rheumatol. 2020

48. Mathian A, Mahevas M, Rohmer J, Roumier M, Cohen-Aubart F, Amador-Borrero B, et al. Clinical course of coronavirus disease 2019 (COVID-19) in a series of 17 patients with systemic lupus erythematosus under long-term treatment with hydroxychloroquine. Ann Rheum Dis. 2020;79(6):837-9.

49. Goyal M. SLE patients are not immune to covid-19: importance of sending the right message across. Ann Rheum Dis. 2020.

50. Liang M, Gao L, Cheng C, Zhou Q, Uy JP, Heiner K, et al. Efficacy of face mask in preventing respiratory virus transmission: A systematic review and meta-analysis. Travel Med Infect Dis. 2020:101751.

51. Leung NHL, Chu DKW, Shiu EYC, Chan KH, McDevitt JJ, Hau BJP, et al. Author Correction: Respiratory virus shedding in exhaled breath and efficacy of face masks. Nat Med. 2020.

52. Leung NHL, Chu DKW, Shiu EYC, Chan KH, McDevitt JJ, Hau BJP, et al. Respiratory virus shedding in exhaled breath and efficacy of face masks. Nat Med. 2020;26(5):676-80.
53. Delen D, Eryarsoy E, Davazdahemami B. No Place Like Home: Cross-National Data Analysis of the Efficacy of Social Distancing During the COVID-19 Pandemic. JMIR Public Health Surveill. 2020;6(2):e19862.

54. Thomson GA. COVID-19: Leaving lockdown-Of Schrodinger, cats, testing and masks. Int J Clin Pract. 2020:e13519.

55. Pincus T, Swearingen CJ, Bergman M, Yazici Y. RAPID3 (Routine Assessment of Patient Index Data 3), a rheumatoid arthritis index without formal joint counts for routine care: proposed severity categories compared to disease activity score and clinical disease activity index categories. J Rheumatol. 2008;35(11):2136-47.

56. Gossec L, Dougados M, Rincheval N, Balanescu A, Boumpas DT, Canadelo S, et al. Elaboration of the preliminary Rheumatoid Arthritis Impact of Disease (RAID) score: a EULAR initiative. Ann Rheum Dis. 2009;68(11):1680-5.

57. Salaffi F, Di Carlo M, Vojinovic J, Tincani A, Sulli A, Soldano S, et al. Validity of the rheumatoid arthritis impact of disease (RAID) score and definition of cut-off points for disease activity states in a population-based European cohort of patients with rheumatoid arthritis. Joint Bone Spine. 2018;85(3):317-22. 